\title{
ENTRY REGULATION AND THE INFLUENCE OF AN INCUMBENT SPECIAL INTEREST GROUP
}

\author{
JOHN EVANS \\ JOHN FINGLETON
}

CESIFO WORKING PAPER NO. 787

CATEGORY 9: INDUSTRIAL ORGANISATION

OCTOBER 2002

Presented at CESifo Venice Summer Institute, July 2001

An electronic version of the paper may be downloaded

- from the SSRN website: www.SSRN.com

- from the CESifo website: www.CESifo.de 


\title{
ENTRY REGULATION AND THE INFLUENCE OF AN INCUMBENT SPECIAL INTEREST GROUP
}

\begin{abstract}
The literature on both entry deterrence and the influence of special interest groups is extensive. In this paper we attempt to marry these strands of literature by developing a model of entry deterrence through interest group influence in an entry re-regulation context. In contrast to other entry deterrence models, we are able to investigate how product market rivalry affects the regulator's equilibrium entry decision, firms' output decisions, entry deterring activities and equilibrium welfare. We find that in equilibrium more collusive industries tend to lobby more but that the regulator attempts to compensate for weak price rivalry by allowing greater entry. The latter effect tends to offset the former, possibly entirely so that the overall welfare effect is ambiguous.
\end{abstract}

JEL Classification: L51, L43, D72.

Keywords: entry regulation, entry deterrence, incumbent lobby group, Quasi-Cournot conjectural variation.

John Evans
The Irish Competition Authority
Parnell House
14 Parnell Square
Dublin 1
Ireland
je@tca.ie

\author{
John Fingleton \\ The Irish Competition Authority \\ Parnell House \\ 14 Parnell Square \\ Dublin 1 \\ Ireland
}

The views expressed herein are those of the authors and do not necessarily reflect the views of the Irish Competition Authority. Most of the work for this paper was undertaken during 1998/1999. At that time John Fingleton was a visiting scholar at the Chicago Business School and John Evans was a research student at the Department of Economics, Trinity College. 


\section{Introduction}

Government regulation frequently restricts entry by fixing the number of firms that can supply a market. Examples include taxis, alcohol retailing, pharmacies, insurance, banking, transport, professions, and importation. There are several possible reasons why the set of regulated markets is so great.

First, free entry could have serious negative welfare effects across a wide set of markets. The excess entry theorem of Chamberlain (1933), generalized by Suzumura and Kiyono (1987), shows that free entry can have negative welfare effects in oligopolistic markets. However, the negative welfare effects are not generally serious and restrictions on entry generate productive and allocative inefficiency and are costly to enforce. Hence it would be difficult to justify entry restrictions on welfare grounds unless the negative externality from an entrant is particularly severe. This could be the case if cream-skimming is possible, or if there is a scarce exclusive input (e.g., spectrum for broadcasting), but this is a relatively narrow subset of all markets where entry is regulated.

Second, it could be that restrictions on entry are used to correct for market failures other than excess entry. The traditional argument might be that raising the return at the margin alters behaviour in a socially beneficial direction.

A third explanation is that entry restrictions do not arise from specific market failures but from capture of the regulatory process by incumbents. This paper attempts to model this process explicitly.

We assume that there is no market failure associated with free entry but that entry has for some reason been regulated in the past. Whether this results from previous lobbying or once-valid market failures is not important, what matters is that the number of firms in the market is regulated and that a regulator must decide on a new allocation. Specifically, we model a regulatory process in which incumbent firms can exert lobbying effort that alters the preferences of regulators who determine the level of entry to a market.

Examples of failures to re-regulate entry to markets where standard economic theory dictates that welfare gains are available are numerous. For instance, re-regulation of taxi markets world wide has proved notoriously problematic despite the existence of obvious excess demand in many cases ${ }^{1}$. In what follows, we purport that the reason such regulatory failures abound is because of the influence that incumbent interest groups exact over the regulatory process. Though we do not believe that incumbent interest groups are solely responsible for regulatory failures of the kind in question, we do believe that modelling the problem as such yields some interesting and useful insights.

We present a simple three stage game theoretic model of the re-regulation process. In the first stage, an interest group representing incumbent firms chooses a level of lobbying effort. In the second stage, a regulator whose objective function depends on interest group lobbying effort, chooses a level of entry to the industry. In the third stage, competition among the $n$ firms in the industry is modelled as monopolistic competition with conjectural variations. We examine how the extent of product market rivalry in the third stage of the game affects the regulator's equilibrium entry decision, firms' output decisions, the interest group's entry deterring activities and equilibrium welfare.

The structure of the paper is as follows. Section 2 outlines the basic assumptions and structure of our model. In Section 3, we present the main results of the paper. Section 4 analyses the effect of product market competition on players' incentives, equilibrium outcomes and welfare. In Section 5, some possible extensions are discussed. Finally, Section 6 concludes with a summary of the main results and potential policy implications.

\section{Model}

In this section we specify a model of cooperative entry deterrence by a special interest group. ${ }^{2}$ Using a three stage game theoretic model of complete information we examine how an interest group representing

\footnotetext{
${ }^{1}$ For a further discussion of this problem in the context of the Dublin taxi market see Fingleton, Evans \& Hogan (1998).

${ }^{2}$ Entry deterrence is cooperative in the sense that inc umbents invest equal shares of effort according to the lobby group's decision. In this paper we do not consider any organisational problems that may arise, e.g. a tendency to free ride.
} 
incumbent firms responds to any attempted re-regulation. In the first stage, the interest group expends effort on lobbying and this biases the regulator's objective function towards the incumbents' profit. In the second stage, the regulator decides upon a level of entry that maximises this unevenly weighted payoff. In the third stage, the incumbents and any new entrants play a homogeneous product, quasi-Cournot output game and thus, the extent of competition in the post-entry game is modelled using a parameter of conjectural variation.

The basic assumptions of the model are as follows.

A1 Demand: Inverse demand $P(Q)$ is downward sloping and continuously differentiable as often as required.

A2 Supply: The market is supplied by $n$ licensed Cournot firms with identical technologies and cost functions $c\left(q_{i}\right)$ such that $c^{\prime}\left(q_{i}\right)>0$ and $c^{\prime \prime}\left(q_{i}\right) \geq 0$ for $q_{i}>0$, where $q_{i}$ is firm output and $Q=\sum_{i=1}^{n} q_{i}$.

A3 Firm Output: Firm output depends on conjectural variations and as such, firm output is determined by the number of firms in the industry, i.e. $q_{i}(n ; \lambda)$. We use the function $\lambda=\frac{\partial Q}{\partial q_{i}}=1+\frac{\partial Q-i}{\partial q_{i}}$ so that $\lambda=0$ is perfect competition, $\lambda=n$ is joint profit maximisation, i.e. monopoly and $\lambda=1$ is the watershed situation of Cournot competition. ${ }^{3}$ For the sake of simplicity of exposition we assume that $\lambda$ is not a function of $n .^{4}$

A4 Effort: The function $\alpha(e)$ is twice continuously differentiable in $e$ with $\alpha(0)=1, \alpha^{\prime}(e)>0$ and $\alpha^{\prime \prime}(e)<0$ for all $e>0$.

A5 Cost of Effort: The function $G(e)$ is twice continuously differentiable in $e$ with $G(0)=0$, $G^{\prime}(e)>0$ and $G^{\prime \prime}(e)>0$.

The regulator's problem is to choose a level of entry $n$ to maximise the sum of consumer surplus $(S)$ and industry profit (I). The regulator's task is complicated by two facts. First, the regulator bears a cost of regulation $(r)$ which we assume is independent of the number of firms. Second, the interest group is able to influence the regulator's behaviour through lobbying. In particular, the interest group exerts lobbying effort $e$ and this effort changes the value of a weight on the incumbent firms' profit component of the regulator's payoff function. There are $n_{0}$ incumbents in the market. Formally, the regulator's payoff is

$$
R=S+\alpha \sum_{i=1}^{n_{0}} \pi_{i}+\sum_{i=n_{0}+1}^{n} \pi_{i}-r
$$

Thus, when no effort is exerted, profits and consumer surplus are weighted equally. However, positive effort biases the regulator's preferences towards the incumbent profit component of its objective function, but decreasing returns set in as lobbying activity grows. ${ }^{5}$ The regulator's payoff function defined above ignores the industry's lobbying costs. This may be justified if they are engaged in wasteful rent-seeking. We investigate the implications of relaxing this assumption at a later stage.

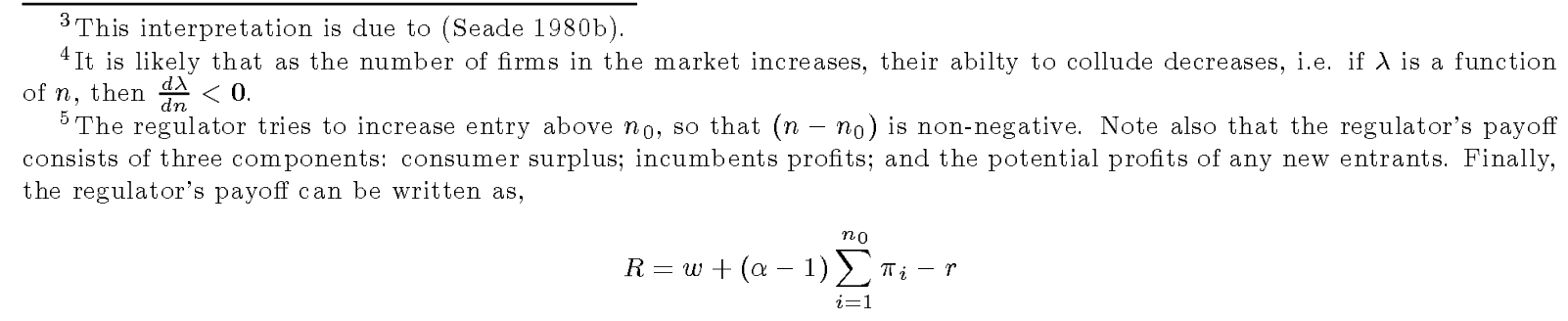

This formulation emphasises the fact that the regulator's payoff consists of welfare $(w=S+\Pi)$ plus any extra weight that is placed on incumbent profit. 
The interest group maximises the difference between incumbent profit and the cost of lobbying. Formally, the interest group's payoff is

$$
L=\sum_{i=1}^{n_{0}} \pi_{i}-G(e)
$$

Lobbying activities are costly to the interest group with $G(e)$ being the cost to the interest group of effort $e^{6}$

The temporal structure of the $n+2$ player game of complete information is as follows.

1. The incumbents' lobby group $(L)$ moves first and chooses how much effort $e$ to expend on lobbying.

2. The regulator $(R)$ chooses the number of firms allowed to enter.

3. Incumbents and any new entrants simultaneously choose an output level $q$.

Payoffs are then determined.

\section{Analysis}

The game is solved by backward induction, so we begin by analysing the behaviour of an individual firm, then the regulator and finally the incumbents' lobby group. We postpone the analysis of varying degrees of product market competition until Section 4 .

\subsection{Stage III: Market Outcome}

Given the regulator's entry level decision $n$, firms play a homogeneous product, quasi Cournot output game. Each firm chooses its output $q_{i}$ to maximise its profit $\pi_{i}\left(q_{i}, n\right)$. Because firms are symmetrically placed in the post-entry game we can concentrate on symmetric equilibria. We therefore drop the firm subscript so that in equilibrium $q_{i}=\tilde{q}, \pi_{i}(\tilde{q})=\pi$ for $i=1 \ldots n$ and $\tilde{Q}=n \tilde{q}$. Equilibrium firm profit must satisfy the following first and second order profit maximisation conditions.

$$
\begin{gathered}
\frac{d \pi(\tilde{q})}{d q}=P(\tilde{Q})+\lambda \tilde{q} P^{\prime}(\tilde{Q})-c^{\prime}(\tilde{q})=0 \\
\frac{d^{2} \pi(\tilde{q})}{d q^{2}}=2 P(\tilde{Q}) \lambda+q \lambda^{2} P^{\prime \prime}(\tilde{Q})-c^{\prime \prime}(\tilde{q})<0
\end{gathered}
$$

A number of points are noteworthy. First, the post-entry game is characterised by a business stealing effect, i.e. $\frac{\partial \tilde{q}}{\partial n}<0$, provided certain conditions about the shape of the market demand function are satisfied, essentially that the market demand not be too convex. Second, industry output is increasing in the number of firms, i.e. $\frac{\partial \tilde{Q}}{\partial n}>0$. These ideas are made explicit in the following lemma which is due to Seade $(1980 \mathrm{~b})$.

\footnotetext{
${ }^{6}$ An alternative specification of lobbying costs could be that the function $G(e)$ is twice continuously differentiable in $e$ with $G(\mathbf{0})=x, G^{\prime}(e)>\mathbf{0}$ and $G^{\prime \prime}(e)>\mathbf{0}$. The difference is that there is a fixed cost of $\boldsymbol{x}$ involved in lobbying, possibly an initial organisation cost. Also, this specification does not require that marginal lobbying is costly. Either of these specifications will be consistent with the existence of an 'interesting' equilibrium. However, if marginal lobbying is costless and there is no fixed cost, then the interest group would be able to achieve any desired level of entry. Moreover, the status quo would endure indefinitely.
} 
Lemma 1(a) Firm output behaves in a "normal" manner as entry occurs $\left(\frac{\partial \tilde{q}}{\partial n}<0\right)$, i.e. firm output decreases as entry occurs, given only stability of equilibrium ${ }^{7}$, if and only if

$$
-\left[\frac{n}{\lambda}+\left(1-\frac{c^{\prime \prime}}{\lambda P^{\prime}}\right)\right]>\frac{Q P^{\prime \prime}}{P^{\prime}}>-\frac{n}{\lambda}
$$

Otherwise, $\frac{\partial \tilde{q}}{\partial n}>0$, i.e. firm output behaves in a "perverse" manner for

$$
-\left[\frac{n}{\lambda}+\left(1-\frac{c^{\prime \prime}}{\lambda P^{\prime}}\right)\right]<\frac{Q P^{\prime \prime}}{P^{\prime}}<-\frac{n}{\lambda}
$$

Lemma 1(b) Equilibrium industry output always increases as entry into stable equilibria occurs, $\frac{\partial \tilde{Q}}{\partial n}>$ 0.8

Equilibrium firm profit is defined as $\pi(n, \tilde{q}(n ; \lambda))$ and is decreasing in the number of firms. This is easily shown as follows,

$$
\frac{d \pi(n, \tilde{q})}{d n}=\frac{\partial \tilde{q}}{\partial n} P+\tilde{q} P^{\prime} \frac{\partial \tilde{Q}}{\partial n}-c^{\prime} \frac{\partial \tilde{q}}{\partial n}=\tilde{q} P^{\prime}\left(\frac{\partial \tilde{Q}}{\partial n}-\lambda \frac{\partial \tilde{q}}{\partial n}\right)
$$

$\left(\frac{\partial \tilde{Q}}{\partial n}-\lambda \frac{\partial \tilde{q}}{\partial n}\right)>0$ by lemmas $1(\mathrm{a})$ and $1(\mathrm{~b})$ and $\tilde{q} P^{\prime}<0$, making $\frac{d \pi}{d n}<0$ as required. However, the result $\frac{d \pi(n, \tilde{q})}{d n}<0$ holds independently of lemma 2 and is true given only stability of equilibrium. We state this result in the following lemma due to Seade (1980b).

Lemma 2 Firm profits decrease as entry into stable equilibria occurs. ${ }^{9}$

\subsection{Stage II: Regulatory Outcome}

The regulator's problem in the second period is to choose $n$ given $e$ has already been chosen by the interest group. Subgame perfection requires that the regulator correctly anticipate the outcome of the game amongst the firms in the third stage. Thus, the regulator maximises its objective function treating $e$ as exogenous and $\tilde{q}$ as endogenous, i.e. the regulator chooses $\tilde{n}$ satisfying ${ }^{10}$,

$$
\tilde{n}=\arg \max _{n \in[0, \infty)}\left[w(n, \tilde{q})+\pi(n, \tilde{q}) n_{0}(\alpha(e)-1)-r\right]
$$

Payoff maximisation condition are,

$$
\begin{gathered}
\frac{d R(\tilde{n})}{d n}=\frac{d w(\tilde{n})}{d n}+(\alpha(e)-1) n_{0} \frac{d \pi(\tilde{n})}{d n}=0 \\
\frac{d^{2} R(\tilde{n})}{d n^{2}}=\frac{d^{2} w(\tilde{n})}{d n^{2}}+(\alpha(e)-1) n_{0} \frac{d \pi^{2}(\tilde{n})}{d n^{2}}<0
\end{gathered}
$$

Proposition 3 For positive levels of effort, the equilibrium number of firms in the industry is less than the socially optimal level, denoted $n^{*}$, which is in turn not greater than the free entry level, denoted $\ddot{n}$. That is, $\ddot{n} \geq n^{*}>\tilde{n} .{ }^{11}$

\footnotetext{
${ }^{7}$ See appendix for proof.

${ }^{8}$ See appendix for proof.

${ }^{9}$ See appendix for proof.

${ }^{10}$ In Section 2 the regulator's objective function was stated as:

This becomes

$$
R=w+(\alpha-1) \sum_{i=1}^{n_{0}} \pi_{i}-r
$$

$$
R=w(n, \tilde{q})+\pi(n, \tilde{q}) n_{0}(\alpha(e)-1)-r
$$

because we are concentrating on the symmetric equilibrium where $\pi_{i}=\pi(n, \tilde{q})$.

${ }^{11}$ See appendix for proof.
} 
From now on we denote the regulator's reaction function as $N(e)$. The slope of the regulator's reaction function $N_{e}$ is given by the following equation

$$
N_{e}=\left[\frac{-\alpha^{\prime}(e) n_{0} \frac{d \pi}{d n}}{\frac{d^{2} w}{d n^{2}}+(\alpha(e)-1) n_{0} \frac{d \pi^{2}(\tilde{n})}{d n^{2}}}\right]
$$

Since, $\frac{d \pi}{d n}<0$ for all $n$ by lemma 4 and $\left(\frac{d^{2} w}{d n^{2}}+(\alpha(e)-1) n_{0} \frac{d \pi^{2}(\tilde{n})}{d n^{2}}\right)<0$ by inequality 5 , the regulator's reaction function will be downward sloping in strategic space- $(e, n)$. The interpretation is that more lobbying by incumbents induces a lower level of permitted entry by the regulator. We state this result in the following lemma.

Lemma 4 The regulator's reaction function is downward sloping in strategic space- $(e, n)^{12}$, i.e. $N_{e}<0$.

A number of other points must also be noticed. First, the regulator's reaction function passes through the point $\left(0, n^{*}\right)$ in strategic space- $(e, n)$, when the regulator is not subject to the influence of the lobby group, it is free to set entry at the socially optimal level. Second, the regulator's reaction function effectively stops at $n=n_{0}$. This occurs because the interest group will not lobby beyond the point where the desired level of entry is below that which already exists. Third, we would like the regulator's reaction function to be convex in strategic space. This will ensure the uniqueness of our solution. ${ }^{13}$

Lemma 5 The regulator's reaction function is convex ${ }^{14}$ in strategic space- $(e, n)$, i.e.

$$
\frac{d^{2} n}{d e^{2}}>0
$$

These features of the regulator's reaction function are illustrated in Figure 1. Finally, we note the effect of different influence functions $\alpha$. We take the two limiting cases of $\alpha^{\prime}(e)=0$, i.e. the regulator is unaffected by lobbying activities and $\alpha^{\prime}(e)=\infty$, i.e. the regulator is completely captured by an infinitely small amount of lobbying. When $\alpha^{\prime}(e)=0$, the value of $N_{e}$ goes to zero. When we combine this fact with the fact that the regulator's reaction function must always pass through the point $\left(0, n^{*}\right)$ we see that the reaction function simply becomes a flat line at $n=n^{*}$. We illustrate this as line $\mathbf{R}_{A}$ in Figure 1 below. On the other hand, when $\alpha^{\prime}(e)=\infty$ the slope of the reaction function also becomes infinite. Again, when we combine this fact with the fact that the regulator's reaction function must always pass through the point $\left(0, n^{*}\right)$, we see that the reaction function simply becomes a vertical line passing through $\left(0, n^{*}\right)$, or simply a section of the $n$-axis in strategic space. We illustrate this in the figure as a vertical line $\mathbf{R}_{B}$ slightly to the right of the $n$-axis. Between these two limiting cases we have values of $\alpha^{\prime}(e)$ lying in the interval $(\infty, 0)$, resulting in reaction functions such as $\mathbf{R}_{C}$.

\subsection{Stage I: Lobbying Decision}

When making its lobbying decision the interest group chooses $e$ to maximise its payoff. Again, subgame perfection requires that the lobby group correctly anticipate the outcome of the game amongst the firms in the third stage and the outcome of the second stage of the game, i.e. the regulator's choice of a level of entry.

$$
\begin{aligned}
\tilde{e} & =\arg \max _{e \in A_{1}} L(e, n(e), \tilde{q}(n(e) ; \lambda)) \\
& =\arg \max _{e \in A_{1}}\left\{n_{0} \pi(n(e), \tilde{q}(n(e) ; \lambda))-G(e)\right\}
\end{aligned}
$$

\footnotetext{
${ }^{12}$ For the sake of completeness this result is also proved in appendix.

${ }^{13} \mathrm{This}$ requirement is not critical to the analysis that follows but does simplify it.

${ }^{14}$ See appendix for proof.
} 


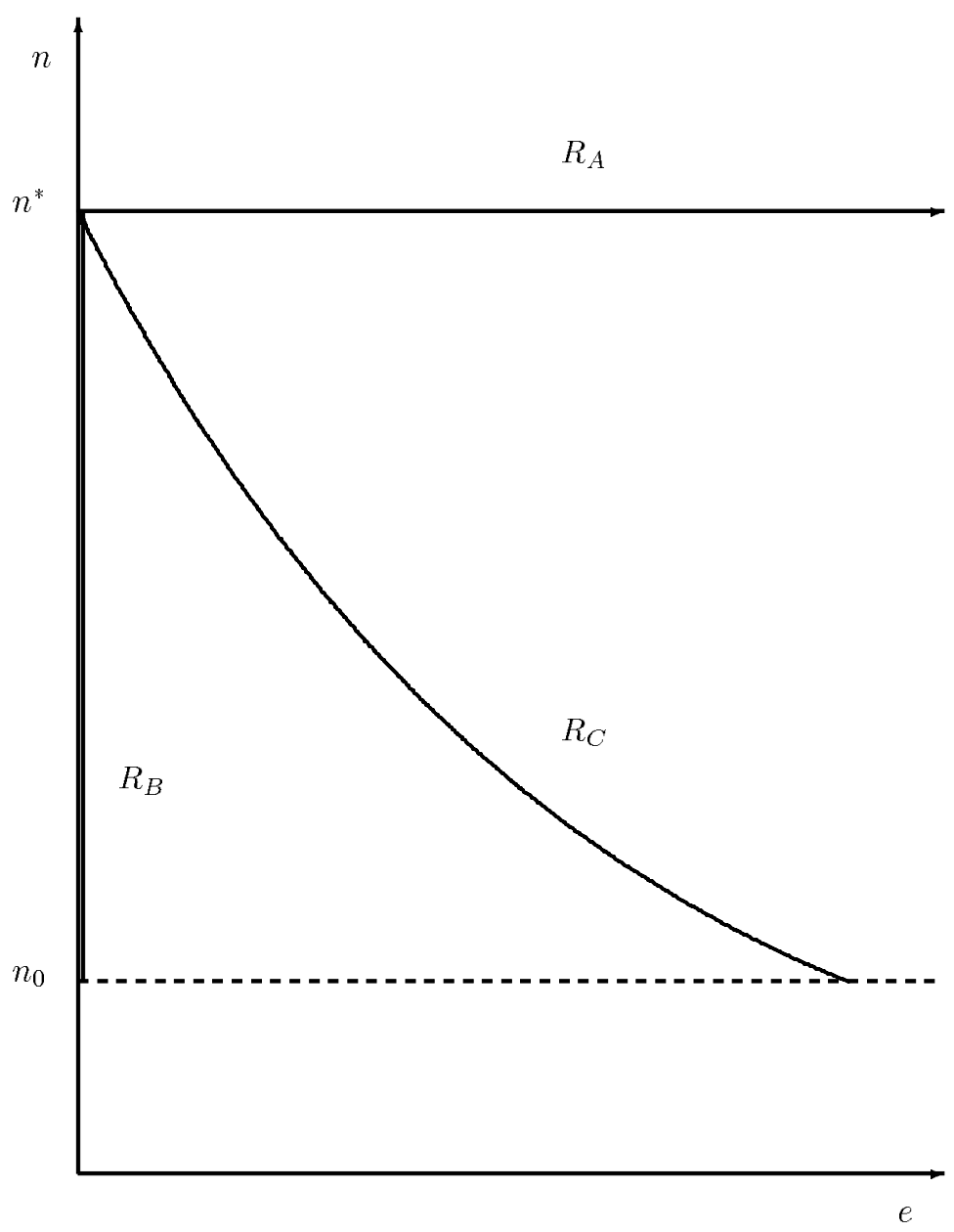

Figure 1: The Regulator's Reaction Function: The regulator's reaction function is downward sloping in strategic space- $(e, n)$, passing through $\left(0, n^{*}\right)$ and stopping at $n_{0}$. The horizontal reaction function $\mathbf{R}_{A}$ corresponds to an ineffectual interest group $\left(\alpha^{\prime}=0\right)$. The vertical reaction function $\mathbf{R}_{B}$ corresponds to an infinitely effective interest group $\left(\alpha^{\prime}=\infty\right)$. $\mathbf{R}_{C}$ corresponds to an intermediate case. 
Payoff maximisation conditions are,

$$
\begin{gathered}
\frac{d L(\tilde{e})}{d e}=n_{0} \frac{d \pi(\tilde{e})}{d n} \frac{d n}{d e}-G^{\prime}(\tilde{e})=0 \\
\frac{d^{2} L(\tilde{e})}{d e^{2}}=n_{0}\left(\left(\frac{d n(\tilde{e})}{d e}\right)^{2} \frac{d^{2} \pi}{d n^{2}}+\frac{d^{2} n}{d e^{2}} \frac{d \pi(\tilde{e})}{d n}\right)-G^{\prime \prime}(\tilde{e})<0
\end{gathered}
$$

We now examine the shape and properties of the interest group's iso-payoff contours. We find the slope of the iso-payoff contours, denoted $I_{e}$ is given by

$$
I_{e}=-\left[\frac{\frac{\partial L}{\partial e}}{\frac{d L}{d n}}\right]=\left[\frac{G^{\prime}}{n_{0} \frac{d \pi}{d n}}\right]
$$

Lemma 6 The interest group's iso-payoffs are downward sloping in strategic space- $(e, n) .{ }^{15}$

Lemma 7 The interest group's iso-payoffs are concave in $e^{16}$

The basic shape of the interest group's iso-payoffs can be seen in Figure 2. Contours of lower payoff are achieved by moving to the right, toward iso-payoff $\mathbf{I}_{C}$ from iso-payoff $\mathbf{I}_{A}$. Contours of higher payoff are achieved by moving to the left toward iso-payoff $\mathbf{I}_{B}$ from iso-payoff $\mathbf{I}_{A}$. Iso-payoff $\mathbf{I}_{B}$ is the contour of maximum payoff because it passes through a point such that $n_{0}$ occurs without lobbying effort. Isopayoff $\mathbf{I}_{C}$ is the contour of zero payoff because it passes through a point such that $n^{*}$ occurs and no lobbying effort is exerted.

If marginal entry is relatively inexpensive for incumbents ( $n_{0} \frac{d \pi}{d n}$ small compared to $\left.G^{\prime}\right)$, iso-payoff contours are less steeply downward sloping, e.g. iso-payoff $\mathbf{I}_{B}$ in Figure 3. Iso-payoff $\mathbf{I}_{A}$ corresponds to the case where entry is relatively expensive. We state this result in lemma form.

Lemma 8 The slope of interest group iso-payoff contours is inversely related to the rate at which firm profits decrease for any $n$. Alternatively stated $\frac{d I_{e}}{d \frac{d \pi}{d n}}<0 .{ }^{17}$

\subsection{Equilibrium}

The Nash equilibrium of the game $(\tilde{e}, \tilde{n})$ is defined by the usual Stackleberg tangency condition. The equilibrium is illustrated as in Figure 4 for $(e, n)$-space. Curve $N(e)$ is the regulator's reaction function. $I$ is the interest group's contour of highest possible payoff given the constraint of the regulator's reaction function and $(\tilde{e}, \tilde{n})$ is the point of tangency representing the Nash equilibrium of the game. We note that at this equilibrium the level of entry allowed by the regulator is less than is socially optimal. Also, the equilibrium involves a positive level of lobbying effort which may be regarded as a wasteful.

It is possible that the game may result in a boundary solution. This will occur if equilibrium entryeffort $(\tilde{e}, \tilde{n})$ is such that $\tilde{n}<n_{0}$. In this case $(\tilde{e}, \tilde{n})$ cannot be an equilibrium because the lobby group has no incentive to reduce the number of incumbents and the equilibrium will be $\left(e_{0}, n_{0}\right)$. This is illustrated in Figure $5 .^{18}$

If the re-regulation game produces a level of entry identical to that which previously prevailed, why attempt re-regulation at all? The welfare consequences of such an attempted re-regulation are negative because positive lobbying effort has been expended and the fixed cost of re-regulation is also spent. We may allow for this possibility by incorporating a new player into the game, the policy maker. In a stage

\footnotetext{
${ }^{15}$ See appendix for proof.

${ }_{16}$ See appendix for proof.

${ }^{17}$ See appendix for proof.

${ }^{18}$ The interest group iso-payoff contour for this boundary solution, contour $B$ in Figure 5 , involves a lower payoff than the contour associated with $(\widetilde{e}, \tilde{n})$, i.e. contour $A$.
} 


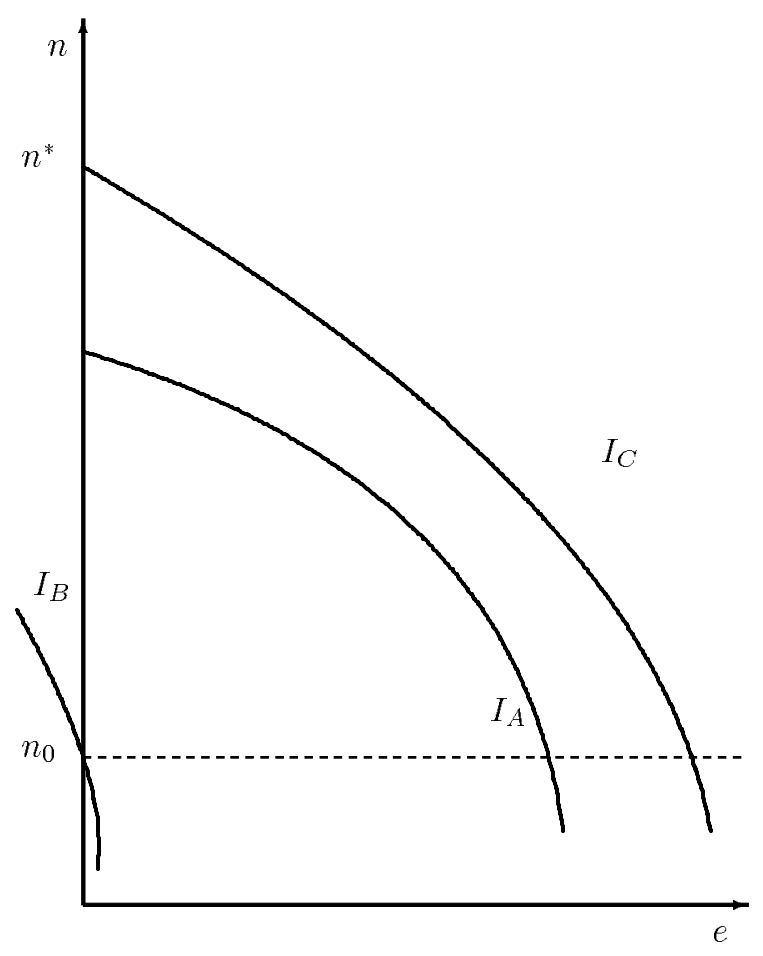

Figure 2: Industry Iso-payoff Contours: Contours of higher payoff are achieved by moving down or to the left. $\mathbf{I}_{B}$ is the contour of highest payoff and $\mathbf{I}_{C}$ is the contour of lowest payoff.

that precedes the lobbying stage, a policy maker makes the decision to re-regulate or do nothing. The regulator may then be viewed as the policy-maker's agent. The policy maker will order re-regulation if positive welfare gains are anticipated.

A 'do nothing' decision on the part of the policy maker does not require that a boundary solution be anticipated. There exists a critical level of entry $n^{c}$ below which negative welfare gains are anticipated and vice versa for a level of entry above $n^{c}$. The size of $n^{c}$ depends on how the policy maker's welfare function is defined. If it is simply the sum of industry profits and consumer surplus ( $w$ from before), then $n^{c}=n_{0}$. If the policy maker is concerned about the fixed cost of regulation $r$, then $n^{c}>n_{0}$. If the policy maker is also concerned about lobbying costs $G$, then $n^{c}$ is even greater. The problem is illustrated in Figure 6. Re-regulation will not be attempted until demand expands so that $\tilde{n} \geq n^{c}$. Somewhat paradoxically, high lobbying costs may have the effect of ensuring that re-regulation will be attempted less frequently. This prompts the following lemma.

Lemma 9 High anticipated equilibrium lobbying costs make attempted re-regulation less likely. ${ }^{19}$

This result is somewhat in contrast to that of (McCormick, Shugart \& Tollison 1984) who suggest that the more "an interest group has to spend annually to maintain its monopoly (holding monopoly rents constant), the greater the gain from deregulation and the more deregulation is likely to occur". However, in our model it is not the case that the right to constant monopoly rents is competed for periodically, rather rents develop over time so that at any given time it is not possible for the regulator to realise the entire value of re-regulation, i.e. the regulator does not anticipate another round of re-regulation.

This analysis also suggests why re-regulation tends to be 'lumpy' in nature, i.e. not on-going, but at discrete intervals. This occurs because the policy maker will wait until the gain from re-regulation is positive. Finally, the analysis also suggests that the number of firms in a market cannot deviate from

\footnotetext{
${ }^{19}$ Proof of this lemma is not provided as the result is obvious from the discussion.
} 


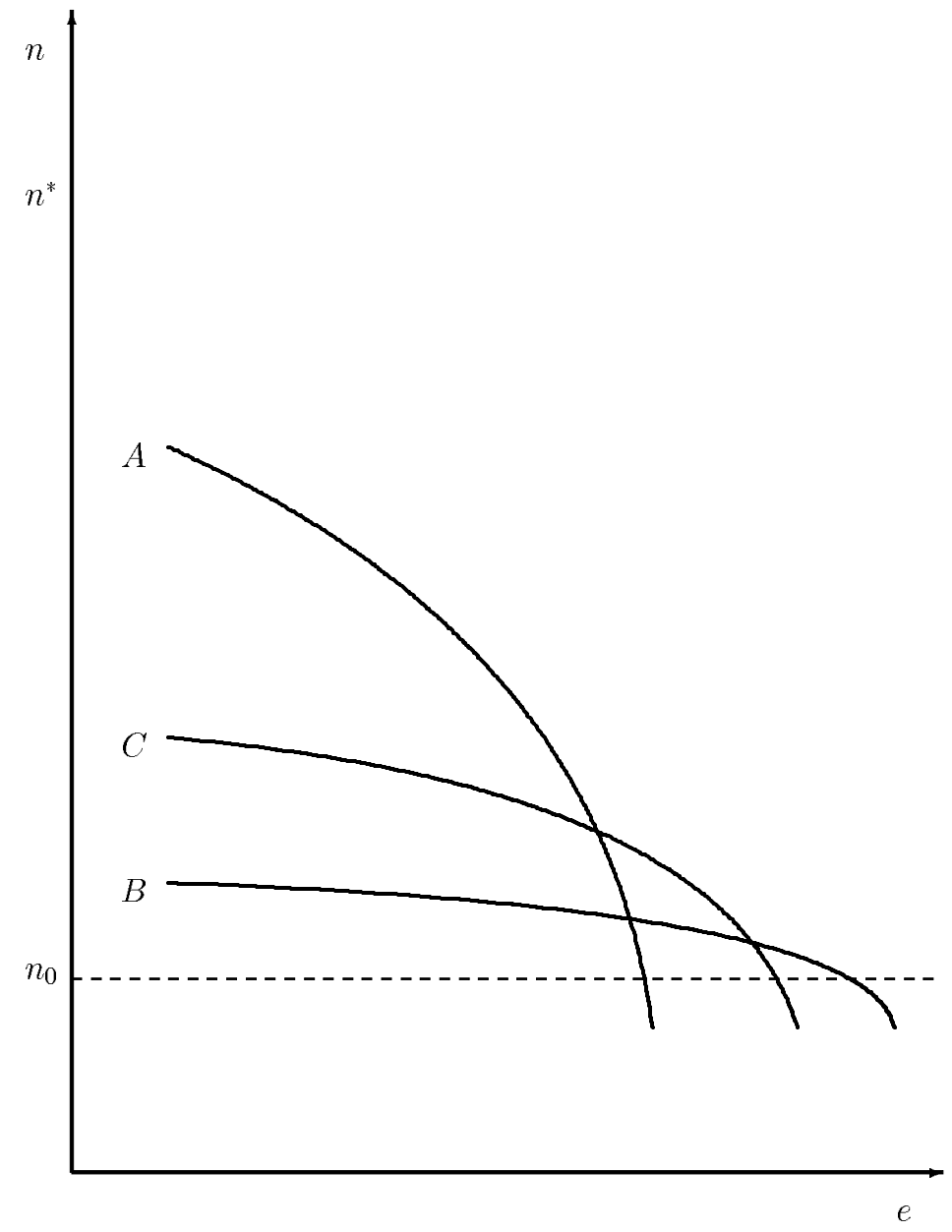

Figure 3: Changing Industry Iso-payoff Contours: The gradually sloping contour $\mathbf{I}_{B}$ indicates that marginal entry is relatively inexpensive in comparison to marginal lobbying. The steeply sloping contour $\mathbf{I}_{A}$ indicates that marginal entry is relatively expensive in comparison to marginal lobbying. $\mathbf{I}_{C}$ represents the intermediate case. 


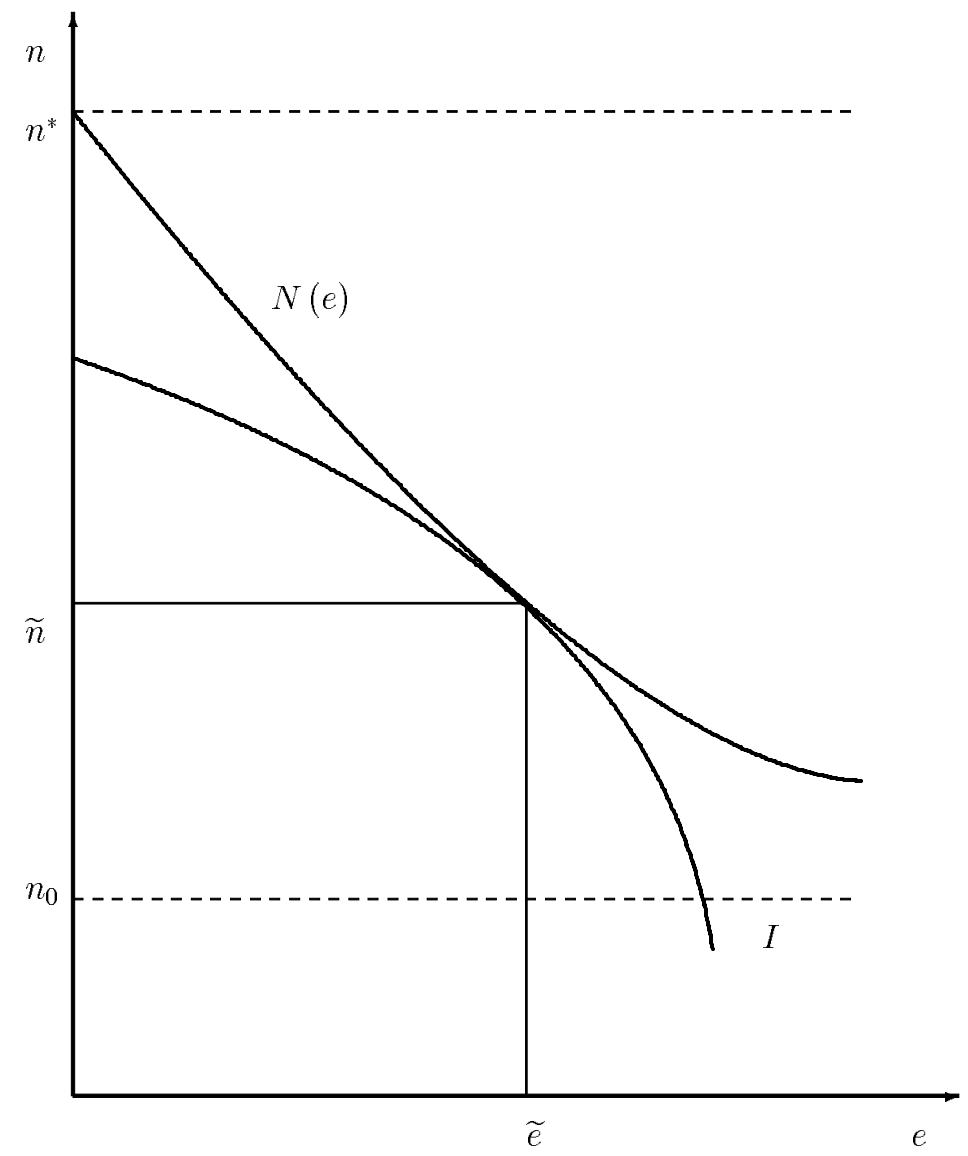

Figure 4: Basic Solution: The equilibrium entry and effort decisions $(\tilde{e}, \tilde{n})$ are defined by the tangency point of the regulator's reaction function $N(e)$ and interest group iso-payoff contour $I$. 


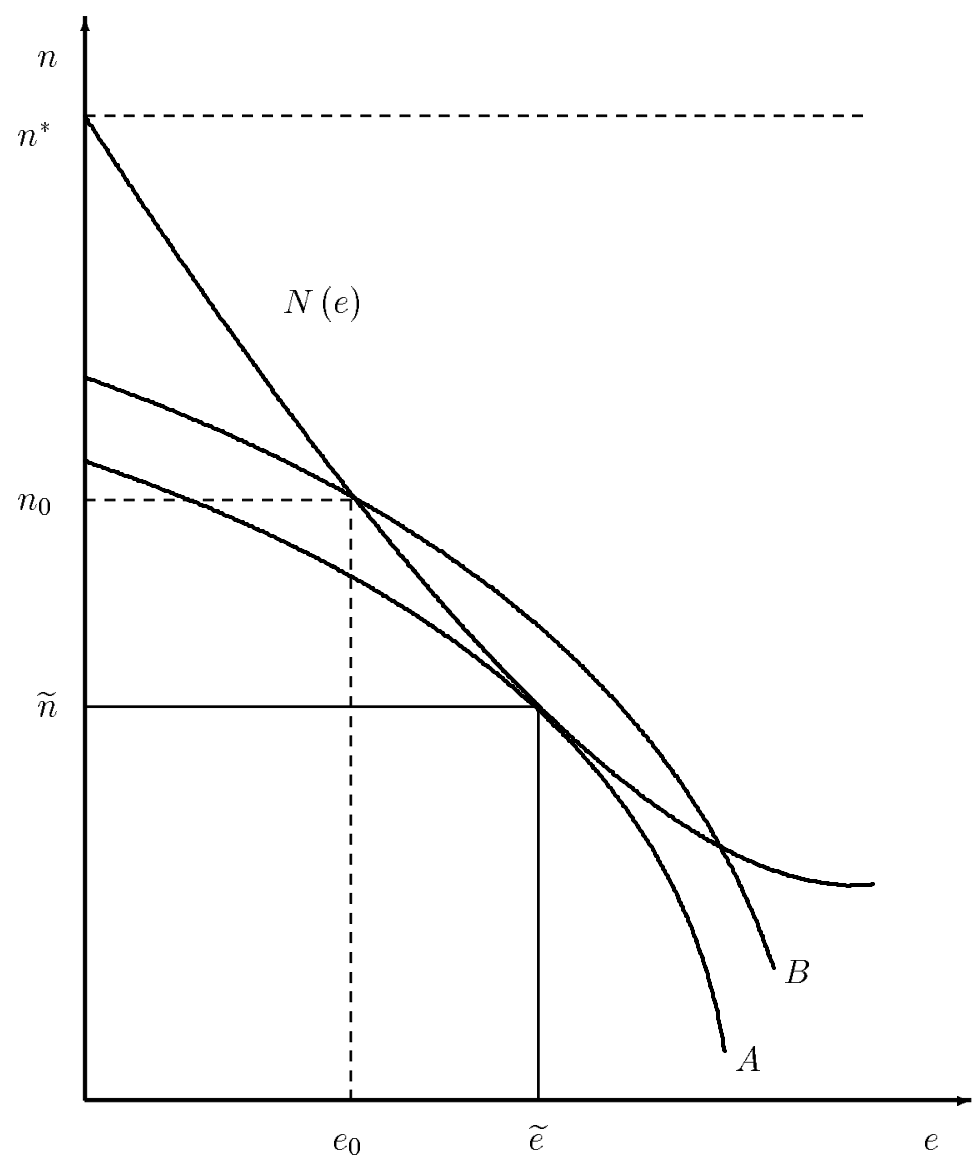

Figure 5: Boundary Solution: $\left(e_{0}, n_{0}\right)$ represents a possible boundary solution of the re-regulation game. This occurs if $\tilde{n}<n_{0}$. Such a solution is impossible as an interest group will not lobby to reduce the number of incumbents. 
the socially optimal level by an arbitrary amount because eventually a situation must arise where the welfare gain to re-regulation must be positive.

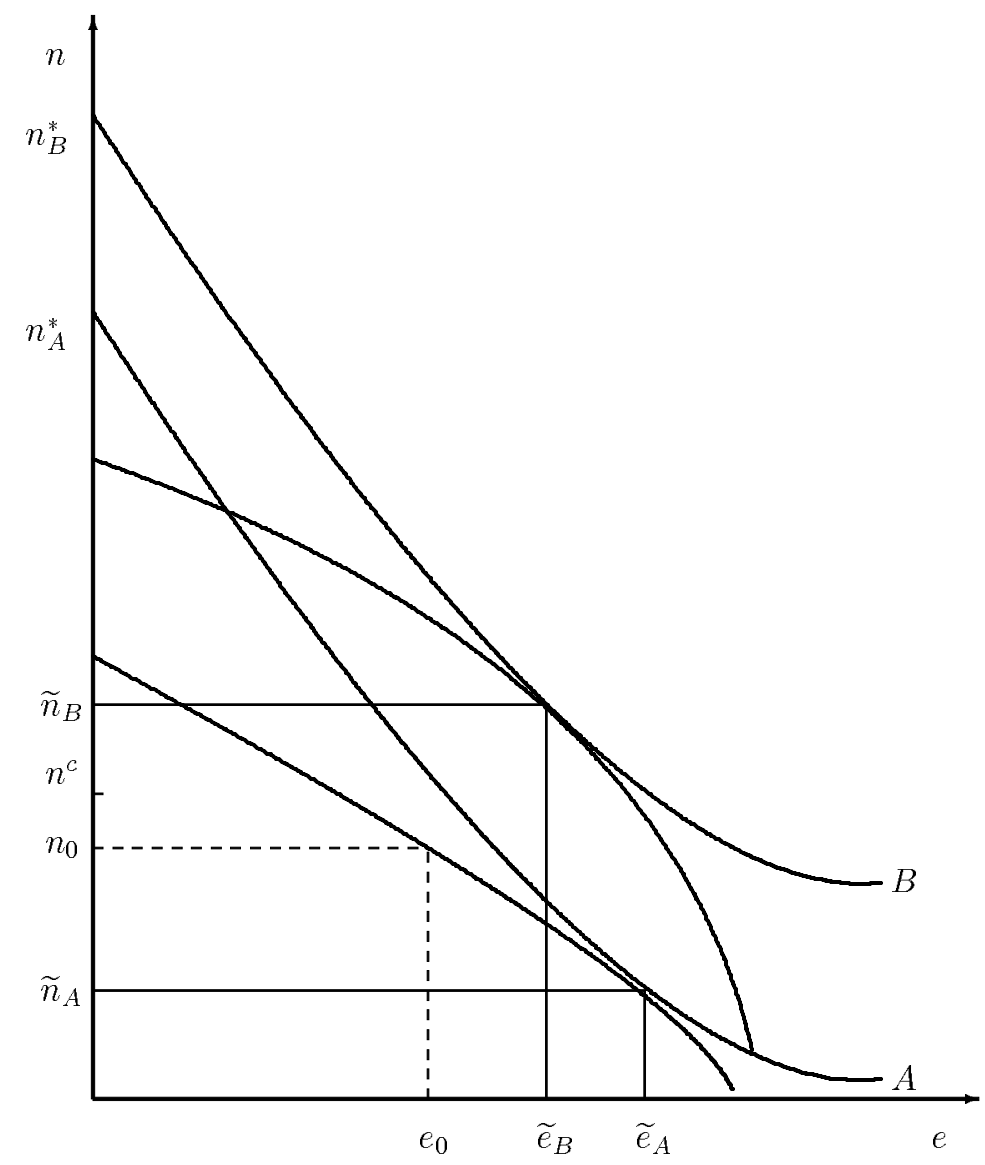

Figure 6: Expanding Market Demand: As demand expands the regulator's reaction function moves up from $A$ to $B$, and the entry-effort equilibrium shifts from $\left(\tilde{e}_{A}, \tilde{n}_{A}\right)$ to $\left(\tilde{e}_{B}, \tilde{n}_{B}\right)$. Re-regulation will not be attempted until $\tilde{n}_{B} \geq n^{c}$, where $n^{c}$ is the minimum entry level required to ensure that the outcome of the re-regulation game is welfare enhancing.

\section{The Effect of Product Market Competition}

In this section we examine how the behaviour of firms, regulator and lobbyists change according to the extent of product market competition. The extent of product market competition is parameterised by conjectural variation so that smaller values of $\lambda$ correspond to greater product market rivalry (or less collusion) and greater values of $\lambda$ correspond to weaker product market rivalry (or greater collusion).

\subsection{Firm behaviour}

The effects of different degrees of product market competition on firm and industry output is predictable. The stronger is product market rivalry the greater are both firm and industry output. We formalise this intuitive result in the following lemma. 
Lemma 10(a) More collusive firms produce less given only stability of equilibria.

Lemma 10(b) More collusive industries produce less given only stability of equilibria.

The extent of product market competition affects how equilibrium firm output changes in response to entry. The less price rivalrous is the product market, i.e. the greater is the extent of conjectural variation, the smaller is the output contraction due to entry or equivalently, the less pronounced is the business stealing effect. This can be rationalised as follows. When an extra firm enters the market, marginal revenue will contract, but the extent of this contraction will depend on the extent of collusion in the market. This occurs because more collusive firms anticipate that other firms will at least partially match any profitable move made by them. So a more collusive firm will anticipate that any given contraction in output on his part will have a disproportionate effect on his marginal revenue, i.e. only a small contraction in output is required to satisfy the marginal revenue equals marginal cost requirement. Conversely, a more competitive firm anticipates that any given contraction in output on his part will affect its marginal revenue only directly. Consequently more competitive firms require a greater contraction in output to satisfy the marginal revenue equals marginal cost requirement. It follows from this that equilibrium industry output increases by a greater amount, the less price rivalrous is the product market.

The extent of product market competition also affects how expensive entry is to incumbents in terms of reduced profits. That is, the sensitivity of equilibrium firm profit to new entry is dependent on the extent of product market competition. The less price rivalrous is the product market, the greater is the reduction in profit due to entry. This follows from the discussion in the previous paragraph.

\subsection{Regulatory behaviour}

When examining the regulator's entry level decision under different degrees of product market competition it is instructive to first consider regulatory behaviour when there is no influence from special interests. When there is no effort exerted by the interest group the regulator is free to set the socially optimal entry level $n^{*}$ as described earlier. The extent of product market competition influences the regulator's choice of $n^{*}$ as follows. As discussed, for a given number of entrants, collusive industries produce less than competitive ones. The regulator therefore has a tendency to compensate for the lack of competition in the product market by allowing more entry, i.e. there is a tendency for $n^{*}$ to be larger. However, the regulator's ability to compensate for weak product market competition is limited by productive efficiency concern. Greater collusion implies that the firms are producing less and, depending on cost conditions, the tendency toward productive inefficiency may be severe.

The effect is similar when the weight on the incumbent profit component of the regulator's objective function is greater than one, i.e. when the interest group exerts lobbying effort. As before, the regulator attempts to compensate for weak product market competition by allowing greater entry and is still constrained by productive efficiency concerns. As discussed in the previous section, the greater weight attached to incumbent profit due to lobbying induces an entry level less than that which is socially optimal. When competition in the product market is weak this effect is exaggerated. This occurs because weak competition implies greater incumbent profit. Thus, the incumbent profit component of the regulator's objective function is larger than it would be under competitive conditions. Whether this effect is large enough to dominate the regulator's tendency to compensate for poor product market competition by allowing a greater entry level depends on the specifications of demand and costs and also on the amount of lobbying undertaken by the interest group. Certainly, the larger the weight on the incumbent profit component of the regulator's objective function, the more likely it is that the second effect will dominate.

\subsection{Lobby group behaviour}

The effect that different degrees of product market competition have on the incentives to lobby of the interest group can be broken into two distinct effects. First, there is a direct effect on the interest group's 
incentives. Second, there is an indirect effect on the interest group's incentives that operates through the regulator's altered behaviour.

The direct effect occurs because the interest group's marginal incentive to lobby is dependent on the level of product market competition, whereas the marginal cost to lobbying is not. However, the precise manner in which the interest group's marginal incentive to lobby is affected is ambiguous. The source of the ambiguity is as follows. The marginal incentive to lobby is dependent on the product of two terms: the marginal increase in profits due to an additional firm not entering; and the marginal effect of lobbying on the regulator's choice of entry level. The former is merely the sensitivity of incumbent profit to entry, which, as discussed is greater when there is weak product market competition. Determining the direction of the latter however, is not possible under general conditions. If this second effect is small, then the first dominates and the interest group tends to lobby more.

The indirect effect operates through the regulator's altered behaviour. As discussed, even though the regulator attempts to compensate for weak product market competition by allowing a greater level of entry, the effect may be reversed because greater incumbent profits weigh more in the regulator's objective function because of the decreased product market rivalry, particularly at high levels of effort. The interest group anticipates this regulatory behaviour. If the regulator's tendency to compensate for weak product market competition dominates then the interest group tends to lobby less. Alternatively, if the regulator tends to allow less entry when there is weak product market competition, then the interest group tends to lobby more. This would reinforce the direct effect discussed in the last paragraph, so that overall, when product market competition is weak, the interest group tends to lobby more. However, there remains much room for ambiguity so that the overall effect is indeterminable for the general case.

\subsection{Welfare Implications}

In light of the previous discussion, the welfare implications of different levels of product market competition are ambiguous. If an interest group representing more collusive firms tends to lobby more, there are three effects. First, because interest groups representing more collusive incumbents may lobby more, lobbying costs are greater and equilibrium welfare is reduced. Second, because more collusive industries produce less, equilibrium welfare is reduced. Third, even though the interest group's equilibrium level of influence is greater, implying a tendency toward a smaller entry decision, the regulator attempts to compensate for greater collusion by allowing a higher level of entry for any level of interest group influence. The former effect dominates if lobbying costs rise slowly and influence rises rapidly in effort, implying an unambiguous negative welfare effect of greater collusion. However, if the latter effect dominates, the overall effect on equilibrium welfare depends on whether the third effect dominates both effects one and two. If an interest group representing more collusive firms tends to lobby less, again there are three effects. First, welfare is improved because lobbying costs are reduced. Second, firms produce less. Third, reduced lobbying effort implies a reduced level of equilibrium influence and a greater level of entry. This effect complements the regulator's tendency to increase entry in more collusive markets. Thus, if effects one and three dominate effect two, greater collusion may be welfare enhancing

\section{$5 \quad$ Discussion and Extensions}

With regard to modelling choices, a number a of points are worthy of mention. First, the timing of the game is crucial. We have modelled the regulation game as a three stage sequential game in which the interest group moves first, then the regulator and finally the firms. We might have collapsed the first two stages into a single stage in which the interest group chooses lobbying effort and the regulator chooses an entry level simultaneously. Investigation of this possibility reveals that no lobbying is done in equilibrium and that the regulator is free to set the socially optimal level of entry. Thus, prior knowledge of re-regulation gives incumbents a first mover advantage.

Second, in our specification of the regulator's objective function we assume that a weighted sum of consumer surplus, incumbent profit and entrant profit is maximised. This is consistent with the normative 
tradition of the theoretical literature on the economics of regulation. ${ }^{20}$ In our model the weight on the incumbent profit component of the regulator's objective function is endogenised and emerges as a result of lobbying activities. However, the process by which lobbying activity translates into influence is not modelled explicitly and is instead assumed to simply occur. ${ }^{21}$ Our approach is in line with other literature in the area. ${ }^{22}$ Moreover, our approach has the advantage of being analytically convenient and also more general in the sense that it is not specific to any particular political/regulatory environment.

Third, our model assumes that an interest group representing incumbent firms engages in lobbying activity on behalf of incumbents, but does not address how such an arrangement comes about. We simply assume that individual incumbent firms have an incentive to engage in group activity and not to lobby independently. Further, given that group action is chosen, we also assume that barriers to group activity are overcome. ${ }^{23}$ An extension of the model developed in this paper might address these issues explicitly.

Finally, in our model of interest group influence we have assumed a single interest group, i.e. that representing incumbents. An extension of the analysis carried out in this paper might include other interest groups, e.g., a potential entrant interest group or a consumer interest group. When exploring such an extension it should be borne in mind that consumer and entrant interest groups are likely to suffer from collective action problems. Consumer groups are likely to face insurmountable barriers to collective action. In comparison to producers, consumers tend to be large in number, have heterogeneous interests and disaggregated benefits to lobbying are likely to be infinitesimal. However, potential entrants are likely to face similar barriers to collective action that incumbents face. Thus, a game involving both groups is plausible.

\section{Conclusion}

This paper develops a model of special interest group influence in an entry re-regulation context. Incumbent firms are represented by a lobby group which attempts to deter entry on their behalf. When the regulator is susceptible to lobby group influence the equilibrium entry decision is socially suboptimal. If lobby group activities are considered socially wasteful then the negative welfare effect of suboptimal entry is compounded. If this additional negative welfare effect is severe enough, no re-regulation will be attempted, implying that high lobbying costs may work to incumbents' advantage.

The effect of different degrees of product market competition on firm, regulatory and interest group behaviour is also examined. We find more collusive incumbents have more to lose due to the entry and accordingly, tend to lobby more. We also find that the regulator attempts to compensate for weak product market competition by allowing greater entry and that this effect can potentially entirely offset the interest group's tendency to lobby more. The welfare effect of different degrees of product market competition is therefore ambiguous.

From a policy perspective, the lessons of the basic model are simple. Regulatory bodies should be designed so that they are not susceptible to interest group influence. There is nothing new in this. However, the analysis of the effects of different degrees of product market competition does reveal some unexpected results. In particular, it may not be the case that any action by antitrust bodies that inhibits price collusion or facilitating practices is welfare enhancing. In our model this occurs because interest groups may lobby more if collusive abilities are reduced, increasing wasteful rent-seeking and inhibiting the regulator's ability to behave in a socially optimal manner.

\footnotetext{
${ }^{20}$ For instance, see Laffont (1996) or Besley and Coate (2000).

${ }^{21}$ For an example of how lobbying can translate into influence see Besley and Coate (2000). In their model, lobbying takes the form of campaign contributions which translate into influence over an elected regulator by providing him with a means of swaying poorly informed voters.

${ }^{22}$ For example, in Becker (1983) and Becker (1985), effort is simply assumed to to translate into influence.

${ }^{23}$ Barriers to collective action, as first emphasised by Mancur Olson (1965), include heterogeneity of group members' interests, group members' intensity of preference and the size of the group and the associated free-rider problem.
} 


\section{References}

Becker, G. S. (1983), 'A theory of competition among pressure groups for political influence', Quarterly Journal of Economics pp. 371-400.

Becker, G. S. (1985), 'Public policies, pressure groups, and deadweight costs', Journal of Public Economics pp. $329-347$.

Besley, T. \& Coate, S. (2000), 'Elected versus appointed regulators: Theory and evidence', NBER Working Paper Series (7579).

Chamberlin, E. (1933), The Theory of Monopolistic Competition, Harvard University Press, Cambridge, Mass.

Fingleton, J., Evans, J. \& Hogan, O. (1998), The Dublin Taxi Market: Re-Regulate or Stay Queuing?, Vol. 3 of Studies in Public Policy, The Policy Institute at Trinity College Dublin.

Laffont, J.-J. (1996), 'Industrial policy and politics', International Journal of Industrial Organisation $14,1-27$.

Mankiw, N. G. \& Whinston, M. D. (1986), 'Free entry and social inefficiency', Rand Journal of Economics $17,48-58$.

McCormick, R. E., Shugart, W. F. \& Tollison, R. D. (1984), 'The disinterest in deregulation', American Economic Review 74, 1075-1079.

Olson, M. (1965), The Logic of Collective Action, Cambridge: Harvard University Press.

Seade, J. (1980b), 'On the effects of entry', Econometrica 48, 479-489.

Suzumura, K. \& Kiyono, K. (1987), 'Entry bariers and economic welfare', Review of Economic Studies 54, 157-167. 


\section{A Appendix of Proofs}

Lemma 1(a) Equilibrium firm output behaves in a "normal" manner as entry occurs $\left(\frac{\partial \tilde{q}}{\partial n}<0\right)$, i.e. firm output decreases as entry occurs, given only stability of equilibrium, if and only if

$$
-\left[\frac{n}{\lambda}+\left(1-\frac{v^{\prime \prime}}{\lambda P^{\prime}}\right)\right]>\frac{Q P^{\prime \prime}}{P^{\prime}}>-\frac{n}{\lambda}
$$

Otherwise, $\frac{\partial \tilde{q}}{\partial n}>0$, i.e. firm output behaves in a "perverse" manner for

$$
-\left[\frac{n}{\lambda}+\left(1-\frac{c^{\prime \prime}}{\lambda P^{\prime}}\right)\right]<\frac{Q P^{\prime \prime}}{P^{\prime}}<-\frac{n}{\lambda}
$$

Proof of Lemma 1(a). Defining the following notation first,

$$
E \equiv \frac{Q P^{\prime \prime}}{P^{\prime}} \quad k \equiv 1-\frac{v^{\prime \prime}}{\lambda P^{\prime}}>0
$$

$E$ is the elasticity of the slope of demand and $\frac{n}{\lambda}$ is the number of effective firms. $k>0$ by assumption 3. A firm's first order profit maximisation condition is

$$
P+q P^{\prime} \lambda-v^{\prime}(q)=0
$$

Differentiating this with respect to entry we find ${ }^{24}$

$$
\begin{aligned}
& P^{\prime} \cdot\left(n \frac{\partial \tilde{q}}{\partial n}+\tilde{q}\right)+\lambda \tilde{q} P^{\prime \prime}\left(n \cdot \frac{\partial \tilde{q}}{\partial n}+q\right)+\lambda \cdot P^{\prime} \cdot \frac{\partial \tilde{q}}{\partial n}-v^{\prime \prime} \cdot \frac{\partial \tilde{q}}{\partial n}=0 \\
&\left(P^{\prime} n+\lambda \tilde{q} P^{\prime \prime} n+\lambda \cdot P^{\prime}-v^{\prime \prime}\right) \frac{\partial \tilde{q}}{\partial n}+P^{\prime} \tilde{q}+\lambda \cdot \tilde{q} \cdot P^{\prime \prime} \tilde{q}=0
\end{aligned}
$$

We now re-write this first order condition as follows

$$
\eta_{q, n}=\frac{n}{\tilde{q}} \cdot \frac{\partial \tilde{q}}{\partial n}=\left[\frac{-\left(E+\frac{n}{\lambda}\right)}{\left(E+\frac{n}{\lambda}+k\right)}\right]
$$

As $\operatorname{sign}\left(\frac{\partial \tilde{q}}{\partial n}\right)=\operatorname{sign}\left(\eta_{q, n}\right)$, to determine the sign of $\frac{\partial \tilde{q}}{\partial n}$ we determine the sign of $\eta_{q, n}$.

$$
\begin{gathered}
\eta_{q, n}>0 \\
\Leftrightarrow\left[\frac{-\left(E+\frac{n}{\lambda}\right)}{\left(E+\frac{n}{\lambda}+k\right)}\right]>0 \\
\Leftrightarrow\left(E+\frac{n}{\lambda}\right)>0,\left(E+\frac{n}{\lambda}+k\right)<0 \quad \text { or } \quad\left(E+\frac{n}{\lambda}\right)<0,\left(E+\frac{n}{\lambda}+k\right)>0
\end{gathered}
$$

We can restrict our attention to the second of these cases. $\left(E+\frac{n}{\lambda}+k\right)<0$ implies instability. The second case may be rewritten as

$$
E<-\frac{n}{\lambda}, E>-\left(\frac{n}{\lambda}+k\right) \text {, i.e. }-\left(\frac{n}{\lambda}+k\right)<E<-\frac{n}{\lambda}
$$

which is as required. Otherwise, $\eta_{q, n}<0$ with strict inequality for $E>-\frac{n}{\lambda}$. and consequently $\frac{\partial \tilde{q}}{\partial n}<0$. We need to impose the strict inequality here because otherwise, we would have two disjoint intervals, i.e. $E>-\frac{n}{\lambda}$ and $E<-\left(\frac{n}{\lambda}+k\right)$, the second of which is precluded by the stability requirement.

$$
q_{n}=-q \frac{\left(P^{\prime}+\lambda \cdot q \cdot P^{\prime \prime}\right)<\mathbf{0}}{\left(P^{\prime} n+\lambda \cdot q \cdot P^{\prime \prime} n+\lambda \cdot P^{\prime}-v^{\prime \prime}\right)<\mathbf{0}}<\mathbf{0}
$$


Lemma 1(b) Equilibrium industry output always increases with entry into stable equilibria, $\frac{\partial \tilde{Q}}{\partial n}>0$.

Proof of Lemma 1(b). We now deal with industry output.

$$
\begin{gathered}
\operatorname{sign}\left(\eta_{Q, n}\right)=\operatorname{sign}\left(\frac{\partial \tilde{Q}}{\partial n}\right) \\
\eta_{Q, n}=1+\eta_{q, n}=\left[\frac{k}{E+\frac{n}{\lambda}+k}\right]
\end{gathered}
$$

Now, stability requires that $\left(E+\frac{n}{\lambda}+k\right)>0$ and we know that $k>0$. Therefore $\eta_{Q, n}>0$ and consequently, $\frac{\partial \tilde{Q}}{\partial \lambda}>0$ as required.

Lemma 2 Firm profits decrease as entry into stable equilibria occurs.

Proof of Lemma 2. From equation 3 we know,

$$
\frac{d \pi}{d n}=\frac{\partial \tilde{q}}{\partial n} P+q P^{\prime} \frac{\partial \tilde{Q}}{\partial n}-c^{\prime} \frac{\partial \tilde{q}}{\partial n}=q P^{\prime}\left(\frac{\partial \tilde{Q}}{\partial n}-\lambda \frac{\partial \tilde{q}}{\partial n}\right)
$$

Using the notation of lemma 2, this can be re-expressed as,

$$
\frac{d \pi}{d n}=\frac{q^{2} P^{\prime}}{\frac{n}{\lambda}}\left[\frac{E+\frac{n}{\lambda}+\frac{n}{\lambda} k}{E+\frac{n}{\lambda}+k}\right]
$$

$\frac{q^{2} P^{\prime}}{\frac{n}{\lambda}}<0$ and stability gives $\left[\frac{E+\frac{n}{\lambda}+\frac{n}{\lambda} k}{E+\frac{n}{\lambda}+k}\right]>0$, making $\frac{d \pi}{d n}$.

Proposition 3 For positive levels of effort, the equilibrium number of firms in the industry is less than the socially optimal level, denoted $n^{*}$, which is in turn not greater than the free entry level, denoted $\ddot{n}$. That is, $\ddot{n} \geq n^{*}>\tilde{n}$

Proof of Proposition 3. The proof that $n^{*} \leq \ddot{n}$ is due to Mankiw and Whinston (1986). Assume that industry output increases in the number of firms, i.e. $\frac{\partial \tilde{Q}}{\partial n}>0$, and that there is a business stealing effect, i.e. $\frac{\partial \tilde{q}}{\partial n}<0$, and that firms do not price below marginal cost, i.e. $P-v^{\prime} \geq 0$. We show that the free entry level of entry is not less than the socially optimal level, i.e. $n^{*} \leq \ddot{n}$. Differentiating the welfare function $w(n)$ with respect to the number of firms we find that for all $n$,

$$
\frac{d w}{d n}=P(n \tilde{q}(n))\left(\tilde{q}(n)+n \frac{\partial \tilde{q}}{\partial n}\right)-c(\tilde{q})-n v^{\prime}(\tilde{q}) \frac{\partial \tilde{q}}{\partial n}
$$

Rearranging these terms and noting that firm profit is given by $\pi(n)=\tilde{q} P(\tilde{Q})-c(\tilde{q})$, we find that for all $n$,

$$
\frac{d w}{d n}=\pi(n)+n\left(P(n \tilde{q}(n))-v^{\prime}(\tilde{q})\right) \frac{\partial \tilde{q}}{\partial n}
$$

Now, $\frac{\partial \tilde{q}}{\partial n}<0$ by assumption. Firms do not price below marginal cost, and therefore the term $\left(P(n \tilde{q}(n))-v^{\prime}(\tilde{q})\right)$ is non-negative by assumption. So the second term on the right hand side of equation B is non-positive and is strictly negative if firms price above marginal cost. Therefore, for all $n, \frac{d w}{d n} \leq \pi(n)$. Now, $n^{*}$ is 
defined by $\frac{d w\left(n^{*}\right)}{d n}=0$, thus $\pi\left(n^{*}\right) \geq 0$. Completion of the proof only requires that it be shown that firm profit is decreasing in $n$ implying that ${ }^{25} n^{*} \leq \ddot{n}$.

$$
\frac{\partial \pi}{\partial n}=\left(P(n \tilde{q}(n))-v^{\prime}(\tilde{q})\right) \frac{\partial \tilde{q}}{\partial n}+\tilde{q}(n) P^{\prime}(n \tilde{q}(n))\left(\tilde{q}(n)+n \frac{\partial \tilde{q}}{\partial n}\right)
$$

The first term on the right hand side of $(\mathrm{C})$ is non-positive because of assumptions two and three. The second term is negative because $\tilde{q}(n) P^{\prime}(n \tilde{q}(n))<0$ and $\left(\tilde{q}(n)+n \frac{\partial \tilde{q}}{\partial n}\right)=\frac{\partial \tilde{Q}}{\partial n}>0$ by assumption one. Therefore $\frac{\partial \pi}{\partial n}<0$, i.e. firm profit is decreasing in $n$ as required.

It remains to show that $n^{*} \geq \tilde{n} . n^{*}$ is defined by the following equation,

$$
\frac{d w\left(n^{*}\right)}{d n}=0
$$

and $\tilde{n}$ is defined by equation 4 ,

$$
\begin{aligned}
\frac{d R(\tilde{n})}{d n} & =\frac{d w(\tilde{n})}{d n}+(\alpha(e)-1) n_{0} \frac{d \pi(\tilde{n})}{d n}=0 \\
& \Rightarrow \frac{d w(\tilde{n})}{d n}=-(\alpha(e)-1) n_{0} \frac{d \pi(\tilde{n})}{d n}
\end{aligned}
$$

Now, $(\alpha(e)-1) n_{0} \frac{d \pi(\tilde{n})}{d n}<0$ implying that $\frac{d w(\tilde{n})}{d n}>0$. $\frac{d w}{d n}>0$ for $n<n^{*}$ implying $n^{*} \geq \tilde{n}$.

Lemma 4 The regulator's reaction function is downward sloping in strategic space-(e, $n)$, i.e. $N_{e}<0$.

Proof of Lemma 4. The slope of the regulator's reaction function $N_{e}$ is given is given by equation 6 , i.e.

$$
N_{e}=\left[\frac{-\alpha^{\prime}(e) n_{0} \frac{d \pi}{d n}}{\frac{d^{2} w}{d n^{2}}+(\alpha(e)-1) n_{0} \frac{d \pi^{2}(\tilde{n})}{d n^{2}}}\right]
$$

Now, $\frac{d \pi}{d n}<0$ for all $n$ by lemma 4 and $\left(-\alpha^{\prime}(e) n_{0}\right)<0$ making the numerator of $N_{e}$ positive. Also, $\left(\frac{d^{2} w}{d n^{2}}+(\alpha(e)-1) n_{0} \frac{d \pi^{2}(\tilde{n})}{d n^{2}}\right)<0$ by the regulator's second order payoff maximisation condition, inequality 5 , making the denominator of $N_{e}$ negative. Therefore, $N_{e}<0$ as required.

Lemma 5 The regulator's reaction function is convex in strategic space-(e,n), i.e.

$$
\frac{d^{2} n}{d e^{2}}>0
$$

Proof of Lemma 5. We differentiate $\frac{d n}{d e}$ with respect to $e$ treating $n$ as a function of $e$, and find the following,

$$
\begin{aligned}
\frac{d n}{d e} & =\left[\frac{-\alpha^{\prime}(e) n_{0} \frac{d \pi}{d n}}{\frac{d^{2} w}{d n^{2}}+(\alpha(e)-1) n_{0} \frac{d^{2} \pi}{d n^{2}}}\right] \\
\frac{d^{2} n}{d e^{2}} & =\frac{-n_{0}}{\left(\frac{d^{2} R}{d n^{2}}\right)^{2}}\left(\begin{array}{c}
\frac{d^{2} R}{d n^{2}} \frac{d \pi}{d n} \alpha^{\prime \prime}+\frac{d^{2} R}{d n^{2}} \frac{d^{2} \pi}{d n^{2}} \frac{d n}{d e} \alpha^{\prime} \\
-\alpha^{\prime}(e) \frac{d \pi}{d n}\left(\frac{d^{3} R}{d n^{3}}\right) \frac{d n}{d e}-\left(\alpha^{\prime}(e)\right)^{2} \frac{d \pi}{d n} n_{0} \frac{d^{2} \pi}{d n^{2}}
\end{array}\right) \\
& =\frac{-n_{0}}{\left(\frac{d^{2} R}{d n^{2}}\right)^{2}}\left(\begin{array}{c}
\frac{d^{2} R}{d n^{2}} \frac{d \pi}{d n} \alpha^{\prime \prime}-\frac{d^{2} \pi}{d n^{2}}\left(\alpha^{\prime}(e)\right)^{2} n_{0} \frac{d \pi}{d n} \\
-\alpha^{\prime}(e) \frac{d \pi}{d n}\left(\frac{d^{3} R}{d n^{3}}\right) \frac{d n}{d e}-\left(\alpha^{\prime}(e)\right)^{2} \frac{d \pi}{d n} n_{0} \frac{d^{2} \pi}{d n^{2}}
\end{array}\right)
\end{aligned}
$$

${ }^{25}$ Free entry implies $\pi(\breve{n})=\mathbf{0}$ and therefore, $\pi\left(n^{*}\right) \geq \pi(\ddot{n})$. Consequently, if $\frac{\partial \pi}{\partial n}<\mathbf{0}$, then $n^{*} \leq \ddot{n}$. 
Ignoring third order effects, this reduces to,

$$
\frac{d^{2} n}{d e^{2}}=\frac{-n_{0}}{\left(\frac{d^{2} R}{d n^{2}}\right)^{2}}\left(\frac{d^{2} R}{d n^{2}} \frac{d \pi}{d n} \alpha^{\prime \prime}-2 \frac{d^{2} \pi}{d n^{2}}\left(\alpha^{\prime}(e)\right)^{2} n_{0} \frac{d \pi}{d n}\right)
$$

The following is sufficient.

$$
\begin{aligned}
0 & >\frac{-n_{0}}{\left(\frac{d^{2} R}{d n^{2}}\right)^{2}}\left(\frac{d^{2} R}{d n^{2}} \frac{d \pi}{d n} \alpha^{\prime \prime}-2 \frac{d^{2} \pi}{d n^{2}}\left(\alpha^{\prime}(e)\right)^{2} n_{0} \frac{d \pi}{d n}\right) \\
& \Leftrightarrow \frac{d^{2} \pi}{d n^{2}}>\frac{-\frac{d^{2} w}{d n^{2}}\left(\alpha^{\prime \prime}\right)}{\left((\alpha(e)-1) n_{0}\left(\alpha^{\prime \prime}\right)-2\left(\alpha^{\prime}(e)\right)^{2} n_{0}\right)}
\end{aligned}
$$

Lemma 6 The interest group's iso-payoffs are downward sloping in strategic space $(e, n)$.

Proof of Lemma 6. The slope of the interest group's iso-payoff contours are given by the expression

$$
I_{e}=\frac{G^{\prime}}{n_{0} \frac{d \pi}{d n}}
$$

Now $G^{\prime}>0$ by assumption. $\frac{d \pi}{d n}<0$ for all $n$.

Lemma 7 The interest group's iso-payoffs are concave in e.

Proof of Lemma 7. Whether or not the interest group's iso-payoff contours are concave in $e$ depends on the sign of $I_{e e}$.

$$
\begin{aligned}
I_{e e} & =\frac{1}{n_{0}}\left(\frac{1}{\frac{d \pi}{d n}}\right)^{2}\left[\frac{d \pi}{d n} \cdot G^{\prime \prime}-G^{\prime} \cdot \frac{d^{2} \pi}{d n} \cdot I_{e}\right] \\
& =\frac{1}{n_{0}}\left(\frac{1}{\frac{d \pi}{d n}}\right)^{2}\left[\frac{d \pi}{d n} \cdot G^{\prime \prime}-\left(G^{\prime}\right)^{2} \cdot \frac{\frac{d^{2} \pi}{d n}}{n_{0} \frac{d \pi}{d n}}\right]
\end{aligned}
$$

The term $\frac{d \pi}{d n} \cdot G^{\prime \prime}<0 .\left(G^{\prime}\right)^{2} \cdot \frac{\frac{d^{2} \pi}{d n}}{n_{0} \frac{d \pi}{d n}}>0$ if $\frac{d^{2} \pi}{d n}<n_{0}\left(\frac{d \pi}{d n}\right)^{2} \cdot \frac{g^{\prime \prime}}{\left(g^{\prime}\right)^{2}}>0$, i.e. if equilibrium firm profit is not too convex. Thus, the term in square brackets negative. Also, $\frac{1}{n_{0}}\left(\frac{1}{\frac{d \pi}{d n}}\right)^{2}>0$ implying $I_{e e}<0$ as required.

Lemma 8 The slope of interest group iso-payoff contours is inversely related to the rate at which firm profits decrease for all $n$. Alternatively stated $\frac{G^{\prime}}{n_{0} \frac{d \pi}{d n}}<0$.

\section{Proof of Lemma 8.}

$$
\begin{aligned}
I_{e} & =\frac{G^{\prime}}{n_{0} \frac{d \pi}{d n}} \\
& \Rightarrow \frac{d I_{e}}{d \frac{d \pi}{d n}}=-\frac{G^{\prime}}{n_{0}}\left(\frac{1}{\frac{d \pi}{d n}}\right)^{2}<0
\end{aligned}
$$


Lemma 10(a) More collusive firms produce less given only stability of equilibria, i.e.

$$
\frac{\partial \tilde{q}}{\partial \lambda}<0
$$

when $E+\frac{n}{\lambda}+k>0$.

Proof of Lemma 10(a). A firm's first order profit maximisation condition is

$$
P+q P^{\prime} \lambda-v^{\prime}(q)=0
$$

Differentiating this with respect to the degree of product market competition $\lambda$ and solving for $\frac{\lambda}{\tilde{\alpha}} \frac{\partial \tilde{q}}{\partial \lambda}$ we find

$$
\begin{aligned}
\frac{\lambda}{\tilde{q}} \frac{\partial \tilde{q}}{\partial \lambda} & =\frac{\lambda}{\tilde{q}} \frac{-\tilde{q} P^{\prime}}{P^{\prime} n+P^{\prime} \lambda+\tilde{q} \lambda P^{\prime \prime} n-v^{\prime \prime}} \\
& =\frac{-1}{E+\frac{n}{\lambda}+k}<0
\end{aligned}
$$

Obviously, $\operatorname{sign}\left(\frac{\lambda}{\tilde{q}} \frac{\partial \tilde{q}}{\partial \lambda}\right)=\operatorname{sign}\left(\frac{\partial \tilde{q}}{\partial \lambda}\right)$

Lemma 10(b) More collusive industries produce less given only stability of equilibria, i.e.

$$
\frac{\partial \tilde{Q}}{\partial \lambda}<0
$$

Proof of Lemma 10(b).

$$
\frac{\partial \tilde{Q}}{\partial \lambda}=n \frac{\partial \tilde{q}}{\partial \lambda}<0
$$




\section{CESifo Working Paper Series}

(for full list see www.cesifo.de)

719 Tapio Palokangas, The Political Economy of Collective Bargaining, May 2002

720 Gilles Saint-Paul, Some Evolutionary Foundations for Price Level Rigidity, May 2002

721 Giorgio Brunello and Daniela Sonedda, Labor Tax Progressivity, Wage Determination, and the Relative Wage Effect, May 2002

722 Eric van Damme, The Dutch UMTS-Auction, May 2002

723 Paolo M. Panteghini, Endogenous Timing and the Taxation of Discrete Investment Choices, May 2002

724 Achim Wambach, Collusion in Beauty Contests, May 2002

725 Dominique Demougin and Claude Fluet, Preponderance of Evidence, May 2002

726 Gilles Saint-Paul, Growth Effects of Non Proprietary Innovation, May 2002

727 Subir Bose, Gerhard O. Orosel, and Lise Vesterlund, Optimal Pricing and Endogenous Herding, May 2002

728 Erik Leertouwer and Jakob de Haan, How to Use Indicators for 'Corporatism' in Empirical Applications, May 2002

729 Matthias Wrede, Small States, Large Unitary States and Federations, May 2002

730 Christian Schultz, Transparency and Tacit Collusion in a Differentiated Market, May 2002

731 Volker Grossmann, Income Inequality, Voting Over the Size of Public Consumption, and Growth, May 2002

732 Yu-Fu Chen and Michael Funke, Working Time and Employment under Uncertainty, May 2002

733 Kjell Erik Lommerud, Odd Rune Straume, and Lars Sørgard, Downstream Merger with Oligopolistic Input Suppliers, May 2002

734 Saku Aura, Does the Balance of Power Within a Family Matter? The Case of the Retirement Equity Act, May 2002

735 Sandro Brusco and Fausto Panunzi, Reallocation of Corporate Resources and Managerial Incentives in Internal Capital Markets, May 2002

736 Stefan Napel and Mika Widgrén, Strategic Power Revisited, May 2002 
737 Martin W. Cripps, Godfrey Keller, and Sven Rady, Strategic Experimentation: The Case of Poisson Bandits, May 2002

738 Pierre André Chiappori and Bernard Salanié, Testing Contract Theory: A Survey of Some Recent Work, June 2002

739 Robert J. Gary-Bobo and Sophie Larribeau, A Structural Econometric Model of Price Discrimination in the Mortgage Lending Industry, June 2002

740 Laurent Linnemer, When Backward Integration by a Dominant Firm Improves Welfare, June 2002

741 Gebhard Kirchgässner and Friedrich Schneider, On the Political Economy of Environmental Policy, June 2002

742 Christian Keuschnigg and Soren Bo Nielsen, Start-ups, Venture Capitalits, and the Capital Gains Tax, June 2002

743 Robert Fenge, Silke Uebelmesser, and Martin Werding, Second-best Properties of Implicit Social Security Taxes: Theory and Evidence, June 2002

744 Wendell Fleming and Jerome Stein, Stochastic Optimal Control, International Finance and Debt, June 2002

745 Gene M. Grossman, The Distribution of Talent and the Pattern and Consequences of International Trade, June 2002

746 Oleksiy Ivaschenko, Growth and Inequality: Evidence from Transitional Economies, June 2002

747 Burkhard Heer, Should Unemployment Benefits be Related to Previous Earnings?, July 2002

748 Bas van Aarle, Giovanni Di Bartolomeo, Jacob Engwerda, and Joseph Plasmans, Staying Together or Breaking Apart: Policy-makers' Endogenous Coalitions Formation in the European Economic and Monetary Union, July 2002

749 Hans Gersbach, Democratic Mechanisms: Double Majority Rules and Flexible Agenda Costs, July 2002

750 Bruno S. Frey and Stephan Meier, Pro-Social Behavior, Reciprocity or Both?, July 2002

751 Jonas Agell and Helge Bennmarker, Wage Policy and Endogenous Wage Rigidity: A Representative View From the Inside, July 2002

752 Edward Castronova, On Virtual Economies, July 2002

753 Rebecca M. Blank, U.S. Welfare Reform: What's Relevant for Europe?, July 2002

754 Ruslan Lukach and Joseph Plasmans, Measuring Knowledge Spillovers Using Patent Citations: Evidence from the Belgian Firm's Data, July 2002 
755 Aaron Tornell and Frank Westermann, Boom-Bust Cycles in Middle Income Countries: Facts and Explanation, July 2002

756 Jan K. Brueckner, Internalization of Airport Congestion: A Network Analysis, July 2002

757 Lawrence M. Kahn, The Impact of Wage-Setting Institutions on the Incidence of Public Employment in the OECD: 1960-98, July 2002

758 Sijbren Cnossen, Tax Policy in the European Union, August 2002

759 Chandima Mendis, External Shocks and Banking Crises in Developing Countries: Does the Exchange Rate Regime Matter?, August 2002

760 Bruno S. Frey and Lars P. Feld, Deterrence and Morale in Taxation: An Empirical Analysis, August 2002

761 Lars Calmfors and Åsa Johansson, Nominal Wage Flexibility, Wage Indexation and Monetary Union, August 2002

762 Alexander R. W. Robson and Stergios Skaperdas, Costly Enforcement of Property Rights and the Coase Theorem, August 2002

763 Horst Raff, Preferential Trade Agreements and Tax Competition for Foreign Direct Investment, August 2002

764 Alex Cukierman and V. Anton Muscatelli, Do Central Banks have Precautionary Demands for Expansions and for Price Stability? - Theory and Evidence, August 2002

765 Giovanni Peri, Knowledge Flows and Knowledge Externalities, August 2002

766 Daniel Friedman and Nirvikar Singh, Equilibrium Vengeance, August 2002

767 Sam Bucovetsky and Michael Smart, The Efficiency Consequences of Local Revenue Equalization: Tax Competition and Tax Distortions, August 2002

768 Tapio Palokangas, International Labour Market Regulation and Economic Growth with Creative Destruction, August 2002

769 Rudi Dornbusch, The New International Architecture, September 2002

770 Hans-Werner Sinn, Weber's Law and the Biological Evolution of Risk Preferences: The Selective Dominance of the Logarithmic Utility Function, September 2002

771 Thomas Mayer, The Macroeconomic Loss Function: A Critical Note, September 2002

772 Seppo Honkapohja and Kaushik Mitra, Learning Stability in Economies with Heterogenous Agents, September 2002

773 David Laidler, Inflation Targets Versus International Monetary Integration - A Canadian Perspective, September 2002 
774 Morten I. Lau, Panu Poutvaara, and Andreas Wagener, The Dynamic Cost of the Draft, September 2002

775 Steven Brakman, Harry Garretsen, and Charles van Marrewijk, Locational Competition and Agglomeration: The Role of Government Spending, September 2002

776 Anke S. Kessler and Christoph Lülfesmann, The Theory of Human Capital Revisited: On the Interaction of General and Specific Investments, September 2002

777 Kjell Erik Lommerud, Frode Meland and Lars Sørgard, Unionized Oligopoly, Trade Liberalization and Location Choice, September 2002

778 Antonio Merlo and François Ortalo-Magné, Bargaining over Residential Real Estate: Evidence from England, September 2002

$779 \mathrm{Yu}-\mathrm{Fu}$ Chen and Michael Funke, Exchange Rate Uncertainty and Labour Market Adjustment under Fixed and Flexible Exchange Rates, September 2002

780 Michael S. Michael, International Migration, Income Taxes and Transfers: A Welfare Analysis, September 2002

781 Clemens Fuest and Alfons Weichenrieder, Tax Competition and Profit Shifting: On the Relationship between Personal and Corporate Tax Rates, October 2002

782 Jan Bouckaert and Hans Degryse, Softening Competition by Enhancing Entry: An Example from the Banking Industry, October 2002

783 Johann K. Brunner and Susanne Pech, Adverse Selection in the Annuity Market with Sequential and Simultaneous Insurance Demand, October 2002

784 Gregory D. Hess and Eduard Pelz, The Economic Welfare Cost of Conflict: An Empirical Assessment, October 2002

785 Jan Erik Askildsen, Uwe Jirjahn, and Stephen C. Smith, Works Councils and Environmental Investment: Theory and Evidence from German Panel Data, October 2002

786 Geir H. Bjønnes, Dagfinn Rime, and Haakon O. Aa. Solheim, Volume and Volatility in the FX-Market: Does it matter who you are?, October 2002

787 John Evans and John Fingleton, Entry Regulation and the Influence of an Incumbent Special Interest Group, October 2002 